\title{
“O Boi é Bom para Pensar": Ensaios sobre a Festa em Perspectivas de Formação em Gênero e Sexualidade
}

"The Ox Is Good for Thinking": Essays on the Party in Perspectives of Gender and Sexuality Formation

\section{“El Buey es Bueno para Pensar”: Ensayos sobre la Fiesta en Perspectivas de Género y Formación Sexual}

Ericky da Silva Nakanome ${ }^{1}$ Professor: Universidade Federal do Amazonas - UFAM/AM

nakanome_85@hotmail.com http://lattes.cnpq.br/7306590906018709 https://orcid.org/0000-0002-6754-3427

Adan Renê Pereira da Silva ${ }^{1}$ Professor: Universidade Federal do Amazonas - UFAM/AM adansilva.1@ hotmail.com http://lattes.cnpq.br/1888827930222244 https://orcid.org/0000-0003-2668-5944

Josivaldo Bentes Lima Júnior ${ }^{2}$ Professor: Secretaria de Estado de Educação do Amazonas - SEDUC juninhobentes@hotmail.com CV: http://lattes.cnpq.br/8367808845583287 https://orcid.org/0000-0003-2574-1879

Universidade Federal do Amazonas - UFAM, Brasil ${ }^{1}$ 


\title{
Resumo
}

Entendendo a complexidade expressa no rico simbolismo da festa dos bumbás Garantido e Caprichoso, realizada anualmente na cidade de Parintins, Amazonas, este texto é um ensaio que articula vivência dos autores e a realização do Festival Folclórico, com o intuito de pensar possibilidades do uso da arte para falar de gênero e sexualidade e alcançar docentes. Para tanto, utilizaram-se autores e autores que tratam do tema, em uma perspectiva dialógica. De modo geral, entende-se a potência do maior festival do norte em falar de educação, valendo-se da arte, da antropologia, da história, para elencar possibilidades de compreensão tanto da sexualidade quanto do gênero com ênfase nas múltiplas dimensões histórico-culturais que tangem os conceitos.

Palavras-chave: Caprichoso. Garantido. Sexualidade e Gênero. Formação de professores/as.

“The Ox is Good for Thinking": Essays on the Party in Perspectives of Gender and Sexuality Formation

\begin{abstract}
Understanding the complexity expressed in the rich symbolism of the Festa dos Bumbás Garantido and Caprichoso, held annually in the city of Parintins, Amazonas, this text is an essay that articulates the authors' experience and the realization of the Folkloric Festival, in order to think about the possibilities of using art to talk about gender and sexuality and reach teachers. For that, we used authors and authors that deal with the theme, in a dialogical perspective. In general, we understand the power of the biggest festival in the north to talk about education, using art, anthropology, history, to list possibilities of understanding both sexuality and gender with emphasis on multiple historical-cultural dimensions. that tangent the concepts.
\end{abstract}

Keywords: Capricious. Guaranteed. Sexuality and Gender. Teacher training.

\section{"El Buey es Bueno para Pensar": Ensayos sobre la Fiesta en Perspectivas de Género y Formación Sexual}

\section{Resumen}

Entendiendo la complejidad expresada en el rico simbolismo de la Festa dos Bumbás Garantido y Caprichoso, celebrada anualmente en la ciudad de Parintins, Amazonas, este texto es un ensayo que articula la experiencia de los autores y la realización del Festival Folklórico, para pensar en las posibilidades de usar arte para hablar sobre género y sexualidad y llegar a los maestros. Para eso, utilizamos autores y autores que tratan el tema, en una perspectiva dialógica. En general, entendemos el poder del festival más grande del norte para hablar sobre educación, usando arte, antropología, historia, para enumerar las posibilidades de comprender la sexualidad y el género con énfasis en múltiples dimensiones histórico-culturales. que tangente los conceptos.

Palabras clave: Caprichosa Garantizado Sexualidad y Género. Formación del profesorado. 


\section{INTRODUÇÃO}

Este artigo origina-se da reflexão dos autores gestada nas práticas que realizam na docência. $\mathrm{O}$ desafio de falar de temas que envolvem subjetividade, estética, cultura, história como o são aqueles que perpassam a Psicologia, as Artes e a História (docência que realizamos) e que, consequentemente, englobam as pessoas holisticamente (corpo, emoção, físico, mental, "natureza", cultura), implica, necessariamente, que se fale de gênero e sexualidade em sala de aula.

Como explorar o nu artístico que choca moralistas? Como discutir "fetiches" ou o conceito de "normal" que atravessa as sexualidades de forma a inquietar discentes, tirando-as/os de lugares comuns? Como falar das diferentes produções históricas que marcaram a humanidade, como a pederastia entre os gregos? Estas são questões que nos mobilizam enquanto professores, no cotidiano, e que provavelmente deve encontrar eco em outros/as profissionais da educação.

Ressalte-se, entretanto, que o tema não se resume a um incômodo pessoal. É, na verdade, uma questão jurídica, de defesa da igualdade material expressa na Constituição Federal, da leitura dos dados que mostram ser o Brasil o país que mais mata LGBT, que "naturaliza" feminícidio e que segue cultivando a cultura do machismo e da misoginia. Àqueles que "fogem da norma" (Butler, 2010), resta apenas o lugar da marginalidade, exclusão, invisibilidade e/ou violência.

Locais de ensino, como a escola e a universidade, não escapam deste histórico de exclusão (Silva; Neves; Mascarenhas, 2019). Pelo contrário, ainda não se tornaram vetores de acolhimento e de questionamento da heteronormatividade, muitas das vezes corroborando e ampliando violências (Silva, 2019; Louro, 2000). Neste sentido, é urgente que professores e professoras recebam formação adequada, sendo capazes de lidar com os próprios estigmas e preconceitos. Para tanto, é preciso criatividade, de modo a ampliar os horizontes destes/as profissionais.

Uma destas possibilidades criativas é o uso da arte. O título deste artigo O "boi-bumbá é bom para pensar", é inspirado na defesa de Braga (2002), de que o boi possui "estruturas de significado" nas manifestações culturais que defende. Pensando a relação entre História e Antropologia e fazendo uso da etnografia, o autor conduz a uma série de discussões que extrapolam os limites do texto, ajudando a problematizar outras, como a aqui elencada: como a festa pode ajudar a formação docente com foco nos temas de gênero e sexualidade?

Para esboçar uma resposta transitória, pensou-se no desenvolvimento do ensaio aqui realizado, em que se articulam autores e autoras que tratam do tema, em um recorte dialógico. Aventam-se aqui algumas possibilidades, sem a ingênua pretensão de esgotá-las. Espera-se, na verdade, que este ensaio possa ser disparador de muitos outros trabalhos científicos.

\section{ENTRE GÊNERO E DIVERSIDADE SEXUAL: POR QUE FALAR DOS BUMBÁS?}

Este trabalho se alinha a outros de caráter sócio-antropológico que pensam os dispositivos de sexualidade e gênero atrelados a inúmeras produções culturais, em diferentes épocas e em diversificados contextos históricos. Isto, entre outras extensões interpretativas, implica pensar com Louro (2000), que debater os temas perpassa outras variáveis, como geração, nacionalidade, religião, classe e etnia, ou seja, outros marcadores sociais. 
O sujeito humano carregará estes marcadores por onde quer que circule. Não estará isento do peso de ser quem é. Dependendo de como articulam-se as citadas variáveis, a sociedade fará "diferenças" entre as pessoas. Ou alguém discorda que uma pessoa jovem, estadunidense, cristã, rica e branca recebe um tratamento diferenciado em relação a um adolescente, da favela brasileira, candomblecista, pobre e negro?

Esta constatação leva a um debate necessário sobre os espaços formais da educação, como a escola e a universidade. Principalmente a primeira, por ser quem abre espaço para a segunda. Espaço de socialização, aprendizagem e vínculos, para ser cidadã, precisa necessariamente acolher. Entretanto, estar na escola não é necessariamente estar acolhido. Esta atitude precisa ser ativa por parte de gestores/as, professores/as, discentes e demais corpo técnico. Por exemplo, em se deparando com o adolescente do segundo perfil, está o espaço escolar apto, para, de fato, acolher?

Se a resposta ao questionamento for negativa, como tende a ser, é preciso verificar como mudar esta realidade. Uma das possibilidades de fazê-lo é focar nos professores e nas professoras, sujeitos da transformação social em sala de aula. Imersos na sociedade, frutos dos movimentos da cultura, é preciso sensibilizá-los/as/conscientizá-los/as de que o espaço escolar não é estanque. Nas palavras de Silva (2019, p. 336), a escola:

[...] fez apenas uma leitura biologicista da prevenção à AIDS e demais infecções sexualmente transmissíveis (IST), bem como enfocou a prevenção da gravidez, especialmente na adolescência. Esqueceu e esquece-se de associar sexo a prazer, esqueceu-se de ser menos proibitiva, de ser menos autoritária, de ouvir o que crianças e adolescentes pensam, sentem e expressam cotidianamente. A escola incorporou discursos médicos, higiênicos e higienistas, objetivou o prazer. Minorou o fato de o desejo começar no cheiro, no toque imprevisto, no admirar da inteligência. Secundarizou que o menino inteligente também se excita ("esse vive só para estudar", pensava o docente que se esqueceu da adolescência vivida), que a menina também tem um corpo erotizado ("é só se ter relações sexuais apenas com o marido que não pega 'doença'", explana a professora religiosa). Invisibilizou o "menino com trejeitos", chamou a família para dar conta do menino trans, "talvez fosse melhor levar para a psicóloga", diz o docente que está com a Bíblia na gaveta da mesa da sala em que leciona.

Esta crítica é uma constatação de que a escola, tal como a entendemos hoje, é resultado de um processo histórico que também normatizou e normalizou o sexo, o gênero e sexualidade. Chamada a intervir quando da epidemia da aids, optou por mostrar "relações sexuais protegidas" entre homens e mulheres. Reproduziu heteronormatividade, frisou discursos judaico-cristãos, enfatizou a prevenção e o "medo" de infecções sexualmente transmissíveis.

Pergunta-se: onde está a dimensão do prazer? Quando se falou do sexo entre pessoas do mesmo gênero? Em que parte da narrativa falou-se das assimetrias entre homens e mulheres na obtenção do gozo?

Estas perguntas, cujas respostas temos medo de ouvir, auxiliam a constatar a necessidade de trabalhar sexualidade e gênero de um modo menos biologicista. Instrumentos há, talvez falte disponibilidade, tendo em vista que, por ser um tema transversal, qualquer professor/a pode falar sobre estes assuntos. Entretanto, é preciso superar a "leitura" de escola como local de padronização, normatização e normalização, na feliz leitura de Louro (2017). 
A autora conta que a escola foi concebida historicamente como local de produção de diferenças e desigualdades. Separou os que tinham acesso dos que não tinham, adultos de crianças, católicos de protestantes. Nesta separação, para um lado foram meninos e para o outro, as meninas. A escola limita espaços e fala claramente do que cada um pode ou não fazer. Os diferentes sujeitos, ao vivenciarem este espaço, "internalizam" comportamentos e aprendem a ter uma "identidade escolarizada". O papel da escola na formação de sujeitos e o impacto dela nas diversas subjetividades são inquestionáveis e merecem, portanto, reflexões, e críticas constantes.

Dentre estas reflexões, grande é a importância que deve ser dado ao corpo docente. A literatura mostra alguns desafios para a formação (inicial e/ou continuada) de professores e professoras. Entre eles, destaca-se o de desvincular a ideia de que seriam unicamente das disciplinas de Ciências, Biologia e Educação Física o papel de falar de sexualidade (Dinis, 2008), o de discutir gênero e sexualidade em vieses mais culturalistas (Canen; Xavier, 2011) e, o principal para o enfoque aqui dado, de trabalhar o tema na formação de professores e professoras (Furlani, 2003).

Como sugestão, Altmann (2013) elenca a possibilidade de formação docente ligada à diversidade sexual por intermédio da arte: artes plásticas, filmes, curta-metragens, literatura adulta e infantil, entre outros. A diversidade sexual tem sido tema tratado direta ou indiretamente nestes campos, o que permite seu reaproveitamento na esfera educativa. Tais recursos podem contribuir para o trato da sexualidade para além da dimensão biológica.

É com este pensamento que o presente artigo se coaduna. Por isso, no próximo subtópico, elencamos algumas reflexões sobre a temática com foco no boi-bumbá. Afinal, para além de corresponder à possibilidade elencada por Altmann (2013), a festa ultrapassa o contexto amazônico e atinge um público - não só de brincantes, mas também de pesquisadores/as - muitas vezes, de fora do Brasil. Os chamados festivais folclóricos também são muito comuns no Amazonas e, muitos deles, são bastante influenciados pelo parintinense. Assim sendo, é importante discutir o alcance propiciado pela transmissão na mídia televisionada, no rádio e em canais como o YouTube, onde pode ser acessada a festa, inclusive, a qualquer momento. Sobre a expressiva manifestação de festas folclóricas no Amazonas, Silva e Castro (2018, p. 83-84) destacam:

Apenas para exemplificar a expressiva quantidade de festas populares, ater-nos-emos aqui a mostrar algumas delas classificadas como "expressões culturais" no Amazonas: boibumbá de Parintins, Cará de Caapiranga, Peixe-Boi de Novo Airão, Cirandas de Novo Aripuanã, Minifestival da cidade de Manacapuru (com disputa também de cirandas), Boibumbá de Nova Olinda, Boi-bumbá de Fonte Boa, entre muitas outras que existem não só no interior, como também na capital (Silva; Castro, 2018, p. 83-84).

Desta maneira, é importante verificar como toda esta visibilidade pode ser levada para a sala de aula, podendo ser tanto uma identificação para professores e professoras que gostam da festa, como um elemento com potencial de ser utilizado formal ou informalmente na formação e prática docente.

\section{A ARTE NO FESTIVAL DE PARINTINS: CONTRIBUIÇÕES PARA O CAMPO DA FORMAÇÃO DOCENTE}

$\mathrm{Na}$ construção de uma visão de "arte", autores e autoras geraram ricos subsídios no campo conceitual. Tal fato leva a um chamado crítico por conta de quem pensa sobre o conceito, pelas 
múltiplas leituras que suscita. Nesta escrita, corroboramos a visão de Sartre (1993) sobre a arte, pensando-a enquanto possibilidade de engajamento (especialmente na prosa) e de Mário de Andrade (1963), para quem a arte interessa-se por aquilo que ocorre na sociedade. É na concretude do que faz o artista que a arte se apresenta (Gombrich, 2013). Desta forma, não existiria arte e sim artistas.

A relação entre cultura popular e processos educativos já foi defendida e apresentada em outros trabalhos (Silva, 2014; Nakanome; Silva, 2018). O Festival utiliza-se de múltiplos artifícios não só para educar, mas para tornar a relação de ensino e aprendizagem popular, dado seu caráter de integração com o grande público. Neste diapasão, a junção da arte com a cultura popular é de fácil realização, levando em conta que são complementares no contexto parintinense. Braga (2012) salienta que as manifestações populares brasileiras carregam o tom da "porta aberta", ou seja, entre desfrute, veja se gosta, permaneça ou não. A arte sente-se à vontade em fazê-lo.

Sociologicamente, o festival apresenta-se como um fenômeno artístico que se enraíza na sociedade. Cria um processo de produção ritualística, de organização, com símbolos e significados. Propõese também elaborar signos e valores como patrimônios de uma Amazônia por vezes idealizada. Economia, política, relações sociais, religião e a cidade como um todo passam a ter algum tipo de entrelaçamento com o boi-bumbá (Silva, 2012a).

Ocorrendo geralmente no fim de junho e início de julho, recebe um número expressivo de visitantes, nacionais e internacionais. Mistura contribuições de europeus, negros e índios, enfatizando a figura cabocla que emerge deste encontro. O elemento central é a do boi-bumbá. Atualmente há dois, rivais entre si, competindo anualmente pela vitória (Braga, 2002).

Sanches (2012) relata que a festa se liga ao bumba meu boi, uma das mais ricas danças dramáticas do Nordeste e do norte do país. Há uma repetição desde o século XVIII, mesclando-se sagrado e profano. $\mathrm{O}$ autor explica que a origem remete provavelmente ao ciclo do gado, marcado, como também visto por Braga (2002), pela temática central da morte e ressurreição do boi. No Nordeste, o festejo é comum nas cidades do sertão e do semiárido e acontece durante o mês de junho, com seu término coincidindo com a festa de São Pedro, dia 29.

No Amazonas, especula-se que chegou por intermédio de negros maranhenses que migraram durante o período áureo da borracha. Pelo lado do boi Garantido (boi branco, defende as cores vermelho e branco), o criador teria sido Lindolfo Monteverde, pelo do Boi Caprichoso (boi negro, defensor das cores azul e branco), Roque Cid. Os primeiros registros existentes do boi-bumbá na cidade de Parintins aparecem no raiar da primeira década do século XX, difundidos na oralidade popular e trazidos em inúmeras versões no decorrer do tempo. Há registros policiais e políticos, que apontam grupos de "baderneiros" tocando tambores e ecoando a desordem em uma comunidade pequena.

As discussões em torno de gênero já podem ser feitas quando da constatação de mãe Catirina, a grávida negra que deseja comer a língua do boi. Geralmente apresentada como uma figura cômica, passa de protagonista a "personagem tradicional" na festa. Não se deseja recair em uma análise anacrônica do auto, mas entender como historicamente a "mulher da festa" foi concebida. Hoje os bois já começam a atentar para a inadmissibilidade das personagens caricaturizadas, tendo, por exemplo, o Boi Caprichoso representado sua Catirina com uma mulher negra neste ano, Ádria 
Barbosa. Este tema pode ajudar docentes a lidar com as questões das representações das mulheres, pensando-as no diapasão das produções culturais em torno da figura feminina.

O boi, em seu surgimento, esteve associado à "marginalidade" e aos negros. Os primeiros registros históricos, de cunho jornalístico da seção policial, dão conta de que a festa era de "bêbados", "arruaceiros", "gente de cor". Braga (2002) relata um exemplo, ao discutir a notícia mais antiga que se tem do bumba-me-boi, oriunda do Frei Miguel do Sacramento Lopes Gomes, o Padre Carapuceiro: no jornal $O$ Carapuceiro (1840), de Pernambuco, o padre fala do boi como manifestação de um "agregado de disparates".

Mulheres não participavam da festa. Uma história não oficial, contada pela oralidade de populares registra a presença de Camé, uma mulher com o sonho de brincar de boi e que se tornou "tripa", única possibilidade de passar camuflada na festividade. Já neste viés, o tema torna-se importante para falar do atravessamento de gênero por outros determinantes sociais, como classe e raça.

As primeiras mulheres que participaram de modo "oficial" adentram a festa em um processo de "amazonização". São as "misses" (mulheres oriundas, inclusive, de outros estados), que, posteriormente, transformar-se-ão em figuras hoje consagradas em forma de itens femininos, como a cunhã-poranga. Estas mulheres, guardadas as devidas proporções, carregam em um viés fetichizado, com muito destaque para a "beleza". Hoje, há uma preocupação em dar protagonismo a elas, com um envolvimento maior em todos os papéis que circundam o planejamento e a execução dos bois-bumbás.

No tocante à comunidade LGBT, o boi passa a ser um espaço de acolhimento a artistas que se assumem pertencentes a este grupo. Tal situação permite visibilidade, reconhecimento e a identificação dos bumbás também como uma festa feita por e para este público. Ter itens individuais que assim se veem torna possível analisar as performances por intermédio do gênero/orientação sexual e fornece um rico material para docentes que queiram trabalhar o tema na perspectiva da igualdade e do respeito. Uma festa que recepciona a todos e a todas, tentando desconstruir os padrões heteronormativos, certamente é uma janela que se abre para que novos horizontes sejam perceptíveis.

Por fim, gostaríamos de destacar o quanto a pauta do gênero e da diversidade sexual foi, de fato, assumida por Caprichoso e Garantido. Nos diversos quadros que compõem as apresentações das três noites, há momentos em que se dá espaço de fato para discussão dos temas. Pela estrutura que um artigo científico deve conter, exemplificaremos dois destes momentos: um do boi-bumbá Caprichoso, outro do boi-bumbá Garantido. Por ser a toada (estilo musical da festa) o fio que conduz o espetáculo, explicando em suas letras o que significa cada quadro da apresentação, seguem aqui transcritas:

Hera, Gaya, Kala, Hamaterasu/Ráume, Mãe Oxum... Mãe Oxum... Yepá!/ Fogo, queima, aquece/Fruto, manto floresce/ Braços, raízes, o sangue é seiva que desce/Vento, dos cabelos de Iansã/Olhos, turmalinas que brilham/Águas que beijam a praia, o mar de Yemanjá... Odoyá!/ Teus rochedos e montanhas, teus bosques, manga e lama, cura tudo aquilo que inflama.../Mãe, natureza mãe, mãe terra, deusa mãe/dos filhos que protegem teu congá/Divina, mãe que guarda "a cria"/Fauna, flora, vida, minérios submersos, teu colar/Está nos vulcões do Havaí, no gelo do primitivo Odin, nas montanhas sagradas dos Navajos.../Nas cordilheiras dos Andes, no abissal dos mares, no céu, no sol e na lua/Em todos os lugares, nas areias do Saara, vestida em Amazônia!/ Entra uma voz feminina, 
representando "Mãe Terra": "Eu trago bonança, meu sopro esperança... Ceucy primitiva, minha dança se fez universo! Fui Terra-Pangéia, fui Éden, sou pedra! Sou flor, viro guerra, sou a festa de um boi negro, Caprichoso!"/Auê, arauê!/Ave, peixe, inseto e réptil/Auê, arauê!/Campo, alimento, solo fértil/Dança tribo! Canta tribo!//lha, ponta, continente, mar aberto/Dança tribo! Canta tribo!/Casa, mãe e filho, amor eterno!/É tambor do meu boi pra você, ó, mamãe, Mãe Terra! (Terra, Mãe Ancestral, composição de Adriano Aguiar)

Esta toada representa retratos do feminino em perspectiva histórica e de múltiplas culturas. Corresponde à abertura do boi Caprichoso na primeira noite de 2018. Fala da universalidade da mulher, com um foco simbólico no feminino. Ao apontar retratos deste feminino, ajuda a desnaturalizar a figura da mulher, mostrando-a de modo plural. É a mulher flor, mas que também vira guerra, que festeja no boi azul. A apoteose da abertura é a chegada da cunhã-poranga, com uma índia mundurucu, representando Ceucy, mãe de Jurupari, o legislador "demonizado" pelo massacre da "evangelização" da cultura indígena.

Tem-se uma introdução a uma releitura do feminino que se oporá à invisibilidade feminina na história, até os dias atuais. Que negará o feminino subjugado ao masculino, ajudando a entendê-lo por meio do contraste, em uma definição a ser feita por oposição. Que possibilitará falar da mulher entrelaçadamente com a questão étnica, ao dar ouvidos e espaço para que uma índia ocupe um papel que deve ser de uma índia.

A segunda toada, do boi-bumbá Garantido 2019, faz um debate sobre misoginia, homofobia, além de homenagear figuras como Marielle Franco (ativista dos direitos humanos, bissexual e negra, vereadora assassinada da cidade de Rio de Janeiro) e Dandara (travesti, brutalmente torturada e assassinada, vítima de transfobia, com requintes de crueldade ao ter sua morte registrada em vídeo, exposta virtualmente):

\footnotetext{
Vou tomar banho de cheiro/Com aroma de emancipação/O perfume das Rosas Vermelhas/Mulheres guerreiras da minha nação/Provedoras da esperança/Cuidadoras da transformação/Rosa-choque misturado ao vermelho do meu coração/Escute com muita atenção, outros desejos de Catirina/São os mesmos de minha mãe, minha irmã e minha filha/Pelo fim da violência, do machismo e da homofobia/São desejos de Dandaras, Marielles e Marias/Venham sempre com as outras/Que os outros vão respeitar/Rosas do jardim do meu Brasil/Rosas Vermelhas do meu boi-bumbá/Vou cantar essa vontade/Com a força da arte que luta/Pela igualdade de gênero/É necessário gente justa!/Rosas caboclas, negras rosas/Rosas das matas, índias rosas/Rosas vermelhas, guerreiras/Do povo Garantido (Rosas Vermelhas, composição de Enéas Dias, Marcos Moura e João Kennedy).
}

Com singular riqueza poética, trazem-se elementos ricos para uma discussão acerca da violência, do feminicídio e da necessidade de não relativização da morte de pessoas unicamente por sua orientação sexual e gênero. Pessoas mortas por serem quem são, em pleno século XXI. Estes momentos do Festival, todos disponíveis no YouTube, podem e devem ser usados na formação de professores/as para discussão de gênero e diversidade sexual para, a posteriori, propiciar debates em sala de aula, a fim de formarmos cidadãos e cidadãs comprometidos/as com a mudança social.

Estamos cientes de que estas possibilidades são bastante restritas quando se pensa toda a complexidade envolta no Festival Folclórico de Parintins. Entretanto, oscilando entre uma leitura histórica que articula passado e presente e a padronização que um ensaio requer, esperamos ter 
levantado os recortes mais importantes para um trabalho de base que use, entre as várias ferramentas que a arte disponibiliza, o Festival como possibilidade para a formação docente.

\section{CONSIDERAÇÕES FINAIS}

Este ensaio visou articular a vivência dos autores e a realização do Festival Folclórico, com o intuito de pensar possibilidades do uso da arte para falar de gênero e sexualidade e alcançar docentes.

De modo geral, entende-se a potência do maior festival do Norte em falar de educação, valendo-se da arte, da antropologia, da história, para elencar possibilidades de compreensão tanto da sexualidade quanto do gênero com ênfase nas múltiplas dimensões histórico-culturais que tangem os conceitos.

Concordando-se com teóricos e teóricas que entendem a arte como instrumento a ser utilizado na formação de professores e de professoras comprometidos/as com a transformação social, pode-se pensar as festas populares como propulsoras de discussões na formação, por pelo menos três vieses:

O primeiro deles, pela dimensão subjetiva do/a docente. Sendo eles e elas pessoas, também podem enxergar no Festival Folclórico de Parintins um elemento de formação da identidade (Silva, 2014). O segundo, pelos referenciais teóricos adotados nas produções de Garantido e Caprichoso, os quais permitem discutir temas como homofobia, racismo, feminicídio e misoginia. E, um terceiro, pela saída do "tradicional" que o campo das artes propicia por sua maneira crítica de trabalhar temas para além da "padronização" escolar.

Para finalizar, entende-se a necessidade de mais pesquisas neste campo, tendo em vista o alcance e o escopo de um ensaio. É necessário que mais pesquisadoras e pesquisadores imiscuam-se na temática, dando vez e escuta a docentes e também avaliando os cursos de formação que estão sendo ofertados aos professores e professoras, seja em âmbito local, seja em âmbito nacional.

\section{REFERÊNCIAS}

ALTMANN, Helena. Diversidade sexual e educação: desafios para a formação de professores. Sexualidad, Salud y Sociedad - Rev Latinoam [online], Rio de Janeiro, n. 13, p. 69-82, abr. 2013. Disponível em: Lhttp://www.redalyc.org/articulo.oa? id = 293325757003>. Acesso em: 2 jun. 2018.

ANDRADE, Mário de. (1963). "O artista e o artesão”. In: O baile das quatro artes. São Paulo: Martins Fontes.

BRAGA, Sérgio Ivan Gil. (2012). Culturas populares em meio urbano amazônico. In: BRAGA, Sérgio Ivan Gil (org.). Culturas populares em meio urbano. Manaus: EDUA.

.. O boi é bom para pensar: estrutura e história nos bois-bumbás de Parintins. Somanlu: Revista de Estudos Amazônicos, [S.1.], v. 2, n. 2, p. p. 13-26, maio 2012. ISSN 2316-4123. Disponível em: 〈http://www.periodicos.ufam.edu.br/somanlu/article/view/257>. Acesso em: 26 jul. 2019. 
BUTLER, Judith. (2010). Problemas de Gênero: Feminismo e subversão da identidade. Tradução Renato Aguiar. 3. ed. Rio de Janeiro: Civilização Brasileira, 2010.

CANEN, Ana; XAVIER, Gisele Pereli de Moura. Formação continuada de professores para a diversidade cultural: ênfases, silêncios e perspectivas. Rev. Bras. Educ., Rio de Janeiro, v. 16, n. 48, p. 641-661, dez. 2011. Disponível em: <http://dx.doi.org/10.1590/S141324782011000300007>. Acesso em: 26 jun. 2019.

DINIS, Nilson Fernandes. Educação, relações de gênero e diversidade sexual. Educ. Soc., Campinas, v. 29, n. 103, p. 477-492, ago. 2008. Disponível em: <http://dx.doi.org/10.1590/S0101-73302008000200009>. Acesso em: 26 jan. 2019.

FURLANI, Jimena. (2003). Educação sexual: possibilidades didáticas. In: LOURO, Guacira Lopes, FELIPE, Jane, GOELLNER, Silvana Vilodre. Corpo, gênero e sexualidade: um debate contemporâneo na educação. 9 ed. Rio de Janeiro: Vozes.

GOMBRICH, Ernst Hans. (2013). A história da arte. Rio de Janeiro: LTC, 2013.

LOURO, Guacira Lopes. (2000). Pedagogias da Sexualidade. In: LOURO, Guacira Lopes. O corpo educado: pedagogias da sexualidade. Belo Horizonte: Autêntica, 2000.

. (2017). Gênero, sexualidade e educação: uma perspectiva pós-estruturalista. 16 ed. Petrópolis: Vozes.

NAKANOME, Ericky da Silva; SILVA, Adan Renê Pereira da. Um olhar sobre o feminino: o que ensina a cunhã-poranga do boi Caprichoso? Amazônica: Revista de Psicopedagogia, Psicologia Escolar e Educação, Humaitá, v. XXII, n. 2, p. 187-206, jul./dez. 2018. Disponível em: http://www.periodicos.ufam.edu.br/amazonica/article/view/5127. Acesso em: 15 mar. 2019.

SANCHES, Cleber. (2012). A cultura popular no Brasil. Manaus: Valer.

SARTRE, Jean-Paul. (2018). Que é a literatura? São Paulo: Ática.

SILVA, Adan Renê Pereira da. (2014). A construção identitária dos cirandeiros do Festival de Cirandas de Manacapuru. 2014. 128f. Dissertação (Mestrado em Psicologia) - Faculdade de Psicologia da Universidade Federal do Amazonas, Manaus.

. Por uma escola para todos e todas: ensaios sobre gênero, sexualidade e diversidade sexual em uma perspectiva inclusiva. RECH - Revista Ensino de Ciências e Humanidades - Cidadania, Diversidade e Bem-Estar, Humaitá, v. IV, n. 1, jan-jun. 2019. Disponível em: www.periodicos.ufam.edu.br/rech/article/view/5814/4535. Acesso em: 17 jul. 2019.

SILVA, Adan Renê Pereira da; CASTRO, Ewerton Helder Bentes de. (2018). A construção identitária dos cirandeiros do Festival de Cirandas de Manacapuru. São Paulo: Dialogar. 
SILVA, Adan Renê Pereira da; NEVES, André Luiz Machado das; MASCARENHAS, Suely Aparecida do Nascimento. Aproximações históricas entre gênero, diversidade sexual e escola. REVISTA UNINGÁ REVIEW, [S.1.], v. 33, n. 3, p. 10-28, jul. 2019. ISSN 21782571. <http://revista.uninga.br/index.php/uningareviews/article/view/2317>. Acesso em: 26 jul. 2019.

SILVA, José Maria da. (2012). Arte e performance no Festival de Parintins. In: BRAGA, Sérgio Ivan Gil (org.). Culturas populares em meio urbano. Manaus: EDUA. 